\title{
The Perception of Medical Students Towards Virtual Learning During Corona Pandemic at Faculties of Medicine at Alzaiem Alazhari and Khartoum Universities, Khartoum, 2021
}

\author{
Daffalla A'lamElhuda ( $\nabla$ dafoua@yahoo.com ) \\ MBBS ,MPH ,MIH ,MD, Federal Ministry of Health \\ Leenah Mohammed S.M \\ MBBS faculty of medicine Alzaeim Alazhari University \\ Alamin Mustafa .E. M \\ Al-Neelain University
}

\section{Research Article}

Keywords: Medical students , COVID-19, virtual learning , perception, online learning

Posted Date: July 30th, 2021

DOI: https://doi.org/10.21203/rs.3.rs-728334/v1

License: (1) This work is licensed under a Creative Commons Attribution 4.0 International License. Read Full License 


\section{Abstract}

Background: "Is COVID-19 pandemic the end of classical class room based education?" the most frequent question nowadays after the forced restrictions which included educational intuition lockdown $\nabla$ objectives, this paper aimed to study the perception of medical students towards virtual learning during COVID-19 pandemic at faculties of medicine at Alzaiem Alazhari and Khartoum universities in Sudan , 2021.

Methods: This was a descriptive cross-sectional faculty -based study in which self-administered questionnaires were distributed to 357 medical students at faculties of medicine at Alzaiem Alazhari university and university of Khartoum. Respondents were selected using simple random sampling, and data was analyzed using SPSS 26.

Results: This study revealed that the average number of hours that spent on virtual learning before and during the COVID-19 pandemic were statistically significant $(p<0.05)$, with average of 1.9 hours per day before the pandemic and average of more than 3 hours per day during the pandemic (57.9\%) .Moreover, the majority of the participants $77.9 \%(n=279)$ thought that virtual learning did not successfully replace the face to face classical teaching especially the clinical medical students $87.2 \%$ ( $n=312$ ) who claimed that clinical skills cannot be taught virtually and they need the direct patient contact education in order to practice the clinical skills in a proper way.

Conclusion: Virtual learning in these two medical faculties was found to be well perceived, because its pros outweighed its cons, as it was the most appropriate method to use in order to continue the education process during the pandemic.

\section{Background}

Coronaviruses are enveloped positive RNA viruses that have spike proteins extensions on their surface that give them a crown-like appearance under the electron microscope hence the name corona which means crown in Latin (1). The novel Coronavirus disease 2019 (COVID-19) is defined as illness caused by a novel coronavirus now called severe acute respiratory syndrome coronavirus 2 (SARS-CoV-2); which was first identified in Wuhan City, Hubei Province, China. $(2,3,4)$ Presentations of COVID-19 infection range from asymptomatic/mild symptoms to much more severe illness that cause death. Symptoms may appear two days to two weeks after exposure to the virus. (5)

Fever or chills, Cough Shortness of breath and difficulty breathing, Fatigue muscle or body aches, headache, loss of taste or smell, Sore throat, Nausea and vomiting diarrhea are all the most common symptoms of the COVID-19 Infection(6).Since the appearance of the first case of COVID-19 in Sudan in the first quarter of the year 2020 ,social distancing measures and public places lockdown were applied and closing all the universities and schools was one of these measures. The majority of the faculties headed towards continuing education as soon as possible from home and through the internet to ensure continuity of the educational process. Then the concept of virtual learning started to appear more frequently which helped the continuation of medical education and limited the spread of the pandemic as well. Virtual learning is defined as learning that can functionally and efficiently occur in the absence of a traditional classroom environment such as face-face interaction (7). Just like web-based learning, however maybe a touch more formal, and consolidating inner programming stages/gateways. With virtual learning, you are taking an in-person component and making it accessible on the web.

The common types of virtual learning can be classified via the medium that used to deliver them such as: Computer based-learning where there is a software to customize materials to suit and fit the specific needs for each student, the other type is internet-based, here the information is delivered through the web so students or other users benefit from it. Remote online teachers deliver information through the internet like online videos, forums, emails and constant messages.

Moreover, blended is learning having between $30 \%$ and $80 \%$ of the course content delivered online where there is a classroom teachers plus one of the subtypes of virtual learning ,other types include facilitated virtual learning in which there is a computer, internet or remote teacher instruction that is supplemented by a human facilitator who assists the students' learning process by providing tutoring or additional supervisions during the lectures (8).

With the rapid spread of the Coronavirus, countries were actualizing emergency extremes to back off and limit the spread of the disease and arranged for a potential longer-term unsettling influence of school and college cooperation.

Loading [MathJax]/jax/output/CommonHTML/jax.js 
The global pandemic has changed the operating environment all over the globe within a few months. The consequences of a pandemic were unstoppable and uncontrollable for many industries of the world which caused massive economic depression and millions of workers lost their jobs during it .Later, nearly 120 countries discontinued face-to-face learning; COVID-19 had impacted the education of approximately a billion students worldwide. The majority of the educational system was based on E-learning.. Since the Corona pandemic has affected the continuation of the medical schools, there was an unexpected move towards web-based instructing. It was unclear how these consequences influenced the students' education .

\section{Problem Statement:}

Since the Corona pandemic has affected the continuation of the medical schools, there was an unexpected move towards web-based instructing. This was pointing to completely get and cover the discernment of virtual learning in Khartoum state. The benefits of the virtual learning for both students and facilitators will be clear and there will be a comparison between the classical and the virtual learning, and we'll get to know the challenges confronting the virtual learning and how to overcome them and by so virtual learning will get to be a fundamental portion of the medical education.

\section{Rationale}

This was the first study in Sudan about virtual learning \& COVID-19 and it highlighted the benefits and obstacles of the virtual learning for students and caparisoning between the classical (face to face education) and the virtual learning, additionally this paper compared between how students utilizing their hours on virtual learning before and during the pandemic and how the pandemic influenced their medical examinations. Because the pandemic is not going to end soon and the social distancing is required, so virtual learning will become a fundamental portion of medical education.

\section{Methods}

This study was a descriptive cross-sectional faculty based study conducted at faculties of medicine at Khartoum and Alzaiem Alazhari universities.

\section{Study setting}

Medical students who were studying at Khartoum (from first to sixth years) and Alzaiem Alazhari (from first to fifth years) universities at the time of data collection and accepted to participate in the study. Medical students studying at other faculties and post-graduate medical students were excluded. The faculty of medicine at Khartoum university was founded in 1924, it is the oldest and biggest medical school with more than 2000 students. The Alzaiem Alazhari University in Khartoum, Sudan was founded in 1993. The faculty of medical sciences at Alzaiem Alazhari was established by announcement of the university council on 28 February 2001.

\section{Patient and public involvement}

This study included only medical students; no patients or general public were involved and students were involved in filling the questionnaire online .

\section{Sampling}

The population size of medical students at Khartoum university were estimated to be 2341 students compared to 930 medical students at Alzaiem Alazhari university in the same year meaning that the total population were 3271 medical students at both faculties by using a confidence interval $(\mathrm{Cl})$ of $95 \%$ with z-score of 1.96 and the margin of error is $5 \%$. Population proportion is $50 \%$. By using Slovin's sample size equation to calculate the sample size below.

By plotting the numbers and values as follow:

$\mathrm{n}=3271 /\left\{1+\left(3271^{*}\left(.05^{\wedge} 2\right)\right\}, \mathrm{n}=356.4\right.$

The sample size was 357

Data collection tools

Loading [MathJax]/jax/output/CommonHTML/jax.js 
Simple random sampling was applied to this study and the data was collected by a close ended questionnaire modified for Sudanese context from a study conducted in UK (9) which was divided into 4 sections; Sociodemographic, online learning and medical education, students perception of online learning and obstacles to it, impact of online learning in clinical teaching. The questionnaire was sent to the students in their faculties telegram, Facebook and WhatsApp accounts.(Table1) shows general characteristics about the participants 
Table 1

Background characteristics of participants $(n=358)$

\begin{tabular}{|c|c|c|}
\hline Characteristics & Frequency & $\%$ \\
\hline Gender & 210 & 72.2 \\
\hline \multicolumn{3}{|l|}{ Female } \\
\hline Male & 81 & 27.8 \\
\hline Total & 358 & 100.0 \\
\hline \multicolumn{3}{|l|}{ Medical school } \\
\hline Khartoum & 291 & 81.3 \\
\hline Alzaeim Alazhari & 67 & 18.7 \\
\hline Total & 358 & 100 \\
\hline Study level & 33 & 9.2 \\
\hline \multicolumn{3}{|c|}{1} \\
\hline 2 & 90 & 25.1 \\
\hline 3 & 61 & 17 \\
\hline 4 & 22 & 6.1 \\
\hline 5 & 133 & 37.2 \\
\hline 6 & 19 & 5.3 \\
\hline Total & 358 & 100 \\
\hline \multicolumn{3}{|l|}{ Age group } \\
\hline Less than 20 years & 98 & 27.5 \\
\hline Between $20-25$ years & 256 & 71.1 \\
\hline More than 25 years & 3 & 0.8 \\
\hline Total & 357 & 99.4 \\
\hline \multicolumn{3}{|l|}{ Residency } \\
\hline Khartoum sate & 294 & 82.1 \\
\hline Stats other than Khartoum state & 54 & 15.1 \\
\hline Outside Sudan & 9 & 2.5 \\
\hline Total & 357 & 99.7 \\
\hline \multicolumn{3}{|l|}{ Family income } \\
\hline Very low & 2 & 0.6 \\
\hline Low & 105 & 29.3 \\
\hline High & 235 & 65.6 \\
\hline Very high & 16 & 4.5 \\
\hline Total & 358 & 100 \\
\hline Statement & Mean & St. Deviation \\
\hline Easy to engage in the lesson & 2.97 & 1.165 \\
\hline
\end{tabular}




\begin{tabular}{|lll|}
\hline Characteristics & Frequency & $\%$ \\
\hline Teaching is interactive & 2.58 & 1.154 \\
\hline I fell able to ask questions that I want & 2.63 & 1.294 \\
\hline I enjoy the online teaching & 2.78 & 1.350 \\
\hline I would like the online teaching to be more interactive & 3.74 & 1.196 \\
\hline I fell that the online teaching is as effective as face-face teaching & 2.45 & 1.327 \\
\hline I prefer online teaching to face-face teaching & 2.67 & 1.537 \\
\hline Teachers are well prepared for the teaching sessions & 2.85 & 1.268 \\
\hline I fell I am being well prepared for my profession in the future & 2.57 & 1.197 \\
\hline I have many internet problems & 2.99 & 1.332 \\
\hline
\end{tabular}

Demographic data (age, gender, medical school, medical school year, residency, family income) ,Medical students perception towards the virtual learning experience before and after the pandemic ,online platforms used and comparison between them and clinical teaching through the virtual learning.

\section{Statistical analysis}

Data were analyzed using SPSS version 26. The Kolmogorov-Smirnov test was used to reveal if the data were normally distributed. Since the data were non-normally distributed, two non-parametric tests were used. Mann Whitney $\mathrm{U}$ test was used to compare the hours of using online platforms during COVID-19 pandemic across clinical and preclinical participants (for independent groups). The Wilcoxon test was used to compare the number of the average hours spent by participants on online platforms before and during the COVID-19 pandemic. Descriptive data were shown as percentages ,means and standard deviation. Any P value less than 0.05 was considered statistically significant.

Table 2. displaying students' perceptions on their experiences of online teaching, ranked on a Likert scale from 1 to 5 , where $1=$ strongly disagree and $5=$ strongly agree. Likert scores have been shown as mean , St. Error and St. Deviation.

\begin{tabular}{lll} 
Statement & Mean & St. Deviation \\
\hline Easy to engage in the lesson & 2.97 & 1.165 \\
\hline Teaching is interactive & 2.58 & 1.154 \\
\hline I fell able to ask questions that I want & 2.63 & 1.294 \\
\hline I enjoy the online teaching & 2.78 & 1.350 \\
\hline I would like the online teaching to be more interactive & 3.74 & 1.196 \\
\hline I fell that the online teaching is as effective as face-face teaching & 2.45 & 1.327 \\
\hline I prefer online teaching to face-face teaching & 2.67 & 1.537 \\
\hline Teachers are well prepared for the teaching sessions & 2.85 & 1.268 \\
\hline I fell I am being well prepared for my profession in the future & 2.57 & 1.197 \\
\hline I have many internet problems & 2.99 & 1.332
\end{tabular}

\section{Discussion}

This was a descriptive cross-sectional faculty based study, where 358 medical students were involved from two universities, Alzaiem Alazhari and Khartoum and results were analyzed by SPSS with the aim of studying the perception of medical students towards virtual learning during COVID-19 pandemic in Khartoum state. 
The response rate of faculty of medicine at university of Khartoum was $81 \%$, compared to $19 \%$ of faculty of medicine at Alzaiem Alazhari university with $69.6 \%$ females, and $30.4 \%$ males respondents. The low response rate of Alzaiem Alazhari university was assumed to be due to the semester examinations which were synchronous with the data collection time.

Noticeably $37.2 \%$ of the total respondents were from fifth year clinical students. This study revealed that the average number of hours that have been spent on virtual learning before and during the COVID-19 pandemic were statistically significant $(p<0.05)$ (Fig. 1A), with average of 1.9 hour per day before the pandemic and average was more than 3 hours per day during the pandemic.

The average hours that have been spent specifically during the pandemic by both preclinical and clinical students were statistically significant $(\mathrm{P}<0.01)$ (Fig. 1B, Fig. 1C) as well, with clinical students spending less hours than the preclinical because clinical skills must be demonstrated at hospitals or health facilities level where practical sessions are made, and this is consistent with a study conducted in the UK in 2020.(9)

Moreover, this study did not find a significant difference between the average hours that have been spent by preclinical and clinical students before the COVID-19 pandemic ( $P>0.819$ ) (Fig. 1B), and the majority of the students( $83.5 \%)$, cited online teaching platforms (online videos like YouTube), as one of the most attractive methods of the virtual learning.

Additionally, students who had a previous experience with virtual learning before the COVID-19 pandemic, had a high perception of virtual learning during the pandemic and this is consistent with a study made in China (10) which revealed the same results this may explain why the students though that why virtual learning did not replace traditional learning successfully also the majority of the students thought that clinical skills cannot be learnt via online learning (Fig. 2A \& Fig. 2B).

The results also revealed that students want more engaging online teaching sessions like live lectures via quizzes and polls rather than pre-recorded non-interactive videos or lectures, because this will enhance the participants' participation and create more interactions between the facilitators and the students, (mean score of 3.74) (table 2) $(11,12)$.

These were remarkable findings for those in Sudan, because it showed that virtual learning has a lot of benefits like; time and cost saving, no need to travel, flexible and feasible to study at any time, etc.

The strong association of clinical medical students' high perception towards face to face learning was interesting, but not surprising because those clinical skills cannot be learnt without performing them on actual patients and being supervised and directed by seniors and professional doctors.

Generally, it seems that because of the mean score (2.57) (table 2) for "being well qualified for your career in the future", the medical students were concerned that virtual learning may negatively impact their professionalism and trust in their future career.

Consistent with a study made in Poland which revealed that students were less active during online lectures compared to traditional classes (13) and this could be explained by the loss of the psychological effect of the schools' environment because studying from home means you are related to other habits and thus the human brain procrastinate the learning and makes the other home habits a priority $(14,15)$. It was also noticed that the majority of the written examinations have not been affected while the majority of the clinical examinations have been postponed and this is due to the social distancing forced by the pandemic.

These findings provided support for the conceptual premise that virtual learning has not fully replaced the traditional face to face method of teaching. (Mean score of 2.45). The most obvious finding that studying the whole time at home without getting any sun exposure or body movements could lead to vitamin D deficiency in the long term, hence leading to depression as they are related, (16, 17). However, more research on this topic is needed.

\section{Conclusion}

Returning to the question posed at the beginning of this paper, it is now possible to state that COVID-19 pandemic affected human social life by limiting the social distancing, hence many universities in the world started to utilize virtual learning to continue the educational process .

The findings clearly indicated that the average number of hours which have been spent on virtual learning before and during the Loading [MathJax]/jax/output/CommonHTML/jax.js re found to be statistically significant $(p<0.05)$ which means there is a difference 
between utilizing virtual medical websites before and during the pandemic with an increase of usage during the pandemic by $57.9 \%$.

Additionally, the average hours spent by preclinical and clinical students before Covid-19 pandemic were found to be statistically insignificant $(P>0.819)$, and the average of hours spent by preclinical and clinical students during the period statistically significant $(\mathrm{P}<0.01)$.

Major barriers for virtual learning were internet connection ,timing of the lectures, poor interactivity between students and facilitators and family distraction. On the other hand, major advantages of virtual learning were: learning at any time, more comfortable, money saving and no travel was needed. Interactive online lectures were recommended by the students to increase their virtual learning satisfactions and enhance understanding as well. .interestingly, practical examinations were affected by COVID-19 pandemic more than written examinations and most practical examination have been delayed.( Fig. 3A \& 3B)

The most obvious finding from this study was that the majority of the participants $77.9 \%(n=279)$ thought that virtual learning did not successfully replace the face to face clinical teaching with direct patient contact, and $87.2 \%(n=312)$ of the participants believed that clinical skills could not be learnt via virtual learning.

Overall, this study strengthened the idea that virtual learning has a lot of advantages but clinical-wise, it didn't meet the expectations and it can't replace face-to-face teaching with direct patient contact.

This study offered a framework for the assessment of the perception of medical students towards virtual learning during the COVID19 pandemic and these findings will help other researchers design more detailed studies in order to cover the whole spectrum of the perceptions and outcomes of the virtual learning during the COVID-19 pandemic.

\section{Recommendations}

Online webinars and live tutorials are highly recommended rather than the recorded slides as the first method showed high interactions between the facilitators and the students as the data obtained showed.

\section{Strength and limitations of the study:}

- - This was the first study in Sudan about using virtual learning during COVID-19, and it highlighted the benefits and obstacles of virtual learning for students and compared between the classical (face to face education) and the virtual learning. Additionally, this paper compared how students utilizing their hours on virtual learning before and during the pandemic and how the pandemic influenced their medical examinations.

- - Survey responses may have been subject to bias in which not all the participants with different socioeconomic status were reached because of the expensive network fees and the unavailability of smartphones for some medical students.

\section{Abbreviations}

SARS-CoV-2: severe acute respiratory syndrome coronavirus 2 , COVID-19: coronavirus disease 2019, UK: United kingdom.

\section{Declarations}

\section{Ethical approval and consent to participate}

The Institutional Review Board at Khartoum University approved this study. Also, visual informed consent was shown in the questionnaire prior to enrolment

ref: UK/FM/CM, serial No : 1/2021

\section{Consent for publication}

The researcher got visual consent from all participates to publish the data for scientific purposes only.

Availability of data and materials

Loading [MathJax]/jax/output/CommonHTML/jax.js 
The datasets that was analysed during this study are available upon request from the authors.

\section{Competing interests}

No conflict of interest

\section{Funding}

No fund was obtained

\section{Authors' contributions}

A'lamElhuda, S.M., and E.M were involved in the process of the study's design and execution. S.M. and E.M. gathered the data, and E.M. analyzed it. A'lamElhuda, S.M., and E.M. contributed to the manuscript's writing and reviewing . The final version of the manuscript was approved by all authors.

\section{Acknowledgements}

Authors would like to express their gratitude to all participants in both faculties for their contributions and corporations.

\section{References}

1. Richman DD, Whitley RJ, Hayden FG. Clinical Virology, 4th ed. Washington: ASM Press; 2016.

2. Chan-Yeung M, Xu RH. SARS: epidemiology. Respirology. 2003;8:S9-14.

3. Middle East Respiratory Syndrome Coronavirus. Available at: https://www.who.int/emergencies/mers-cov/en/. Accessed 16 Feb 2020.

4. CDC. 2019 Novel Coronavirus, Wuhan, China. CDC. Available at https://www.cdc.gov/coronavirus/2019-ncov/about/index.html. Januar 26, 2020; Accessed: January 27, 2020.

5. CDC. 2019 Novel Coronavirus, Wuhan, China: Symptoms. CDC. Available at https://www.cdc.gov/coronavirus/2019ncov/about/symptoms.html. January 26, 2020; Accessed: January 27, 2020.

6. CDC. Symptoms of Coronavirus. CDC. Available at https://www.cdc.gov/coronavirus/2019-ncov/symptomstesting/symptoms.html. May 13, 2020; Accessed: June 26, 2020.

7. Schlosser, A., \& Simonson, M. (2006). Distance education: Definition and glossary of terms, 2nd ed. Greenwich, CO: Information Age Publishing.

8. "Fast Facts About Online Learning" (International Association for K-12 Online Learning, 2009), 2, 8, http://www.inacol.org/press/docs/ nacol_fast_facts.pdf (accessed June 1, 2010

9. Dost S, Hossain A, Shehab M, Abdelwahed A, Al-Nusair L. Perceptions of medical students towards online teaching during the COVID-19 pandemic: a national cross-sectional survey of 2721 UK medical students. BMJ open. 2020 Nov 1;10(11):e042378.

10. Wang $\mathrm{C}$, Wang W, Wu H. Association between medical students' prior experiences and perceptions of formal online education developed in response to COVID-19: a cross-sectional study in China. BMJ open. 2020 Oct 1;10(10):e041886.

11. McBrien JL, Cheng R, Jones P. Virtual spaces: employing a synchronous online classroom to facilitate student engagement in online learning. IRRODL 2009;10. 36 Muir S, Tirlea L, Elphinstone B, et al. Promoting classroom engagement through the use of an online student response system: a mixed methods analysis. Journal of Statistics Education 2020;28:25-31.

12. Muir S, Tirlea L, Elphinstone B, et al. Promoting classroom engagement through the use of an online student response system: a mixed methods analysis. Journal of Statistics Education 2020;28:25-31

13. Bączek M, Zagańczyk-Bączek M, Szpringer M, Jaroszyński A, Wożakowska-Kapłon B. Students' perception of online learning during the COVID-19 pandemic: a survey study of Polish medical students. Medicine. 2021 Feb 19;100(7).

14. Wood W, Rünger D. Psychology of habit. Annual review of psychology. 2016 Jan 4;67:289-314.

15. Gardner B, Lally P, Wardle J. Making health habitual: the psychology of 'habit-formation'and general practice. British Journal of Loading [MathJax]/jax/output/CommonHTML/jax.js 64-6. 
16. Anglin RE, Samaan Z, Walter SD, McDonald SD. Vitamin D deficiency and depression in adults: systematic review and metaanalysis. The British journal of psychiatry. 2013 Feb;202(2):100-7.

17. Parker GB, Brotchie H, Graham RK. Vitamin D and depression. Journal of affective disorders. 2017 Jan 15;208:56-61.

\section{Figures}
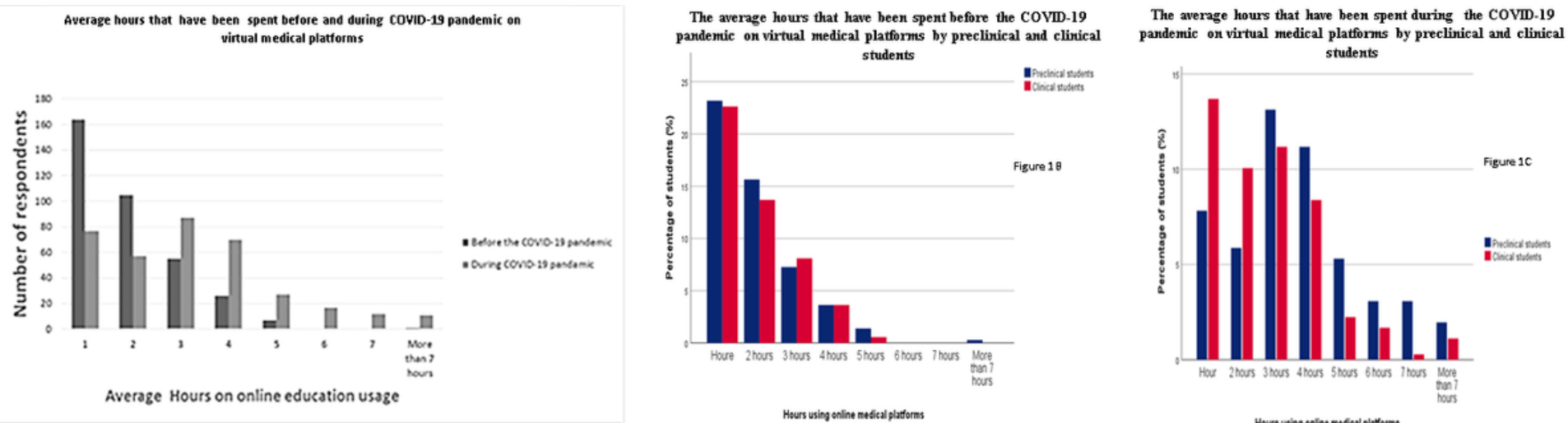

Figure 1

A . compares the average number of hours that have been spent on online learning before and during the COVID-19 pandemic by medical students $(n=358)$. A Wilcoxon test was used which found the difference to be statistically significant $(p<0.05)$. b . The average hours spent by preclinical and clinical students before Covid-19 pandemic is found to be statically insignificant $(P>0.819)$. Figure $1 \mathrm{C}$.this figure shows the average hours that have been spent by preclinical and clinical students during Covid-19 pandemic was found to be statistically significant $(p<0.05)$. Mann Whitney $U$ test was used to compare the hours of using online platforms during COVID-19 pandemic across clinical and preclinical participants (independent groups).

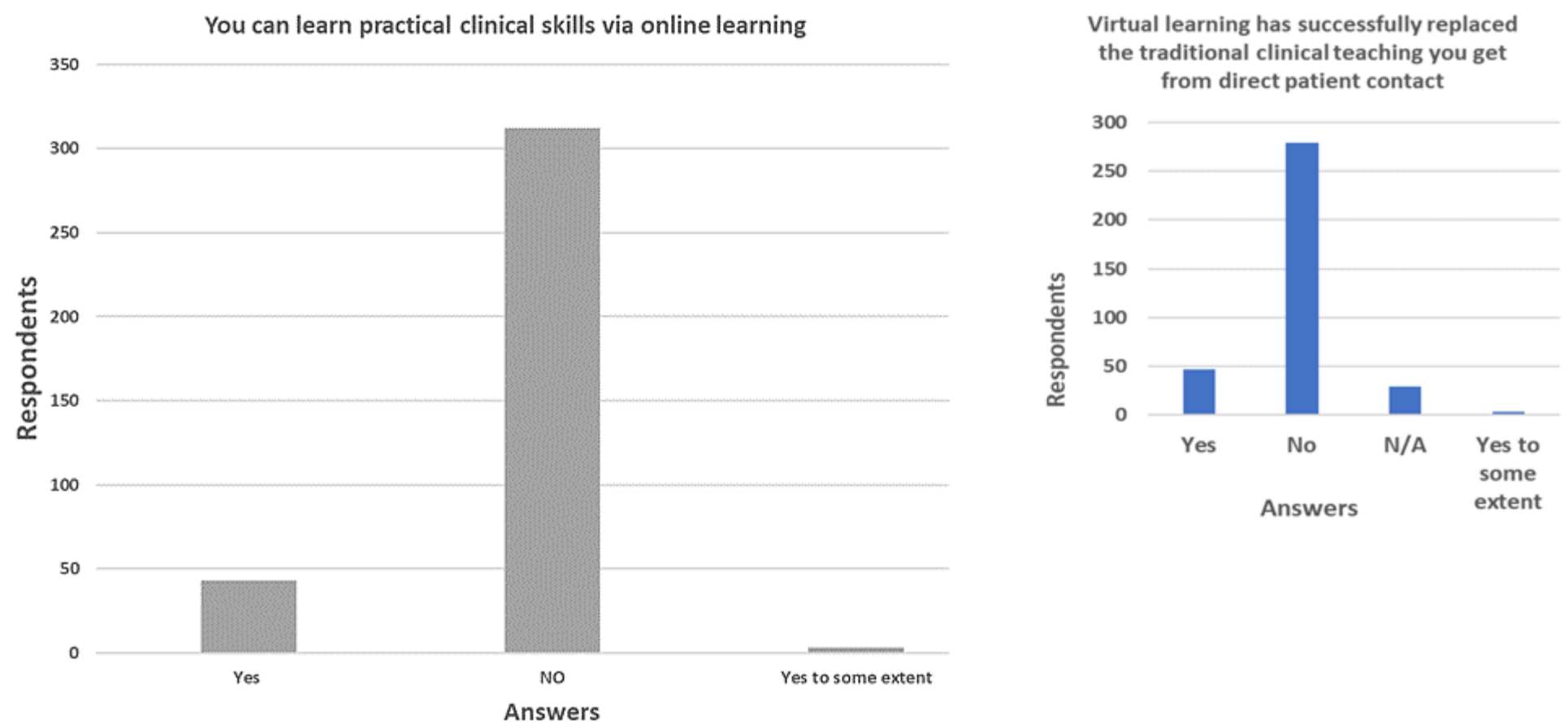

Figure 2

A. shows the participants' responses about if they could learn clinical skills via online learning. B. shows the participants' responses about if virtual learning clinical teaching was effective as traditional clinical teaching from direct patient contact. 
COVID-19 PANDEMIC AND FACULTY'S WRITTEN EXAMINATIONS

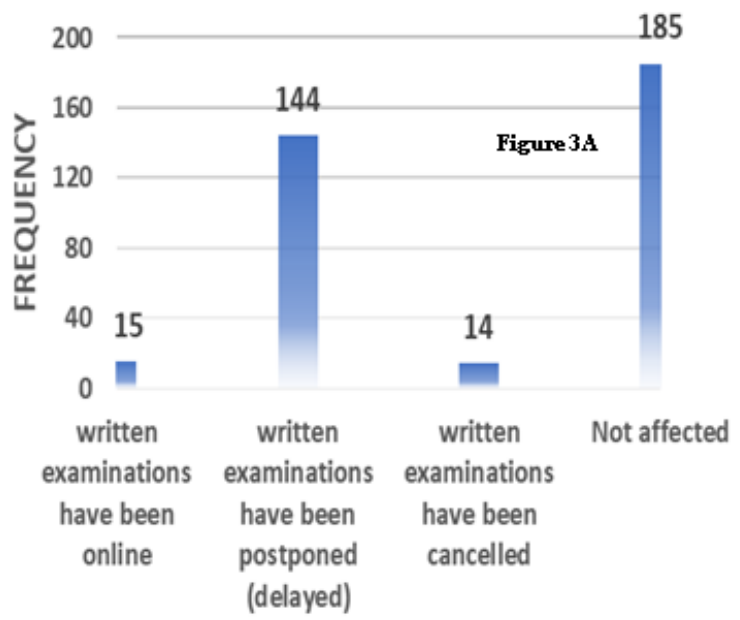

ANSWERS
Covid-19 pandemic and Faculties' practical examinations

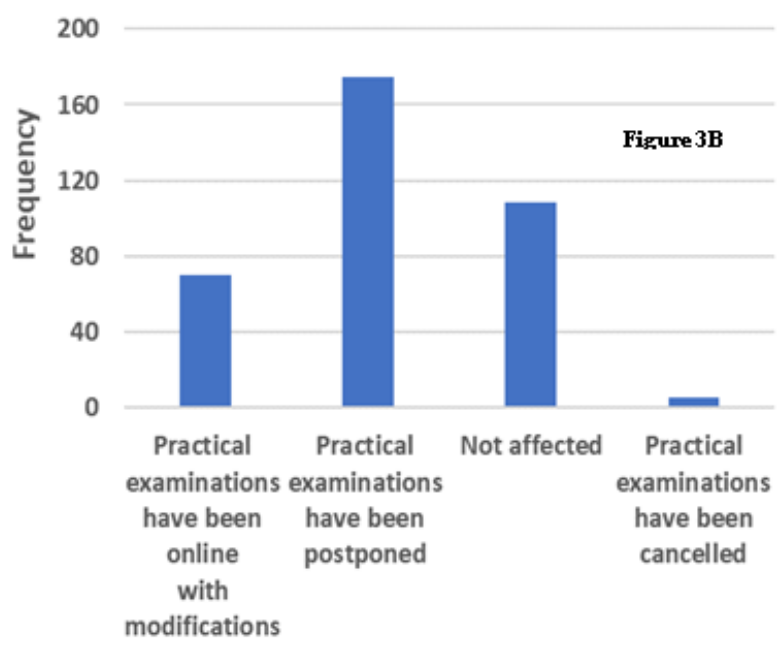

Answers

\section{Figure 3}

A. shows the participants' responses about if faculty swrienexa min ationswereaffectedbyCOVID - 19p and emic. FigureB. showstheparticipants'responsesabout if facty s practical examinations were affected by COVID-19 pandemic 